\title{
INTRAHEPATIC BILIARY STRICTURES WITH UNDERLYING PRE-MALIGNANT BILIARY LESIONS: IS IT TIME TO BUILD GUIDELINES ON DIAGNOSIS AND MANAGEMENT?
}

\author{
ESTENOSES BILIARES INTRA-HEPÁTICAS COM LESÕES BILIARES PRÉ-MALIGNAS SUBJACENTES: É HORA DE \\ CONSTRUIR DIRETRIZES SOBRE DIAGNÓSTICO E TRATAMENTO?
}

\author{
Giuliano LA BARBA $^{1 \oplus}{ }^{\circ}$, Carlo Alberto PACILIO ${ }^{1 \oplus}$, Cecilia BINDA $^{2 \oplus}$, Francesca FAPPIANO ${ }^{1 \oplus}$, Carlo FABBRI $^{2 \oplus}$, \\ Giorgio ERCOLANI ${ }^{1,30}$
}

INTRODUCTION \section{AND LITERATURE REVIEW}

$\mathrm{B}$ iliary intraepithelial neoplasia (BillN) is defined as a precursor lesion of invasive adenocarcinoma and it can develop both in intrahepatic and extrahepatic bile ducts. BillN grossly presents as flat lesions but is usually macroscopically and radiologically unidentifiable ${ }^{10,21}$. Interestingly, in the last decades due to the spread of imaging techniques, focal intrahepatic biliary strictures (FIHS) are more commonly incidentally founded in clinical practice. It is currently unknown which is their correct management and in what percentage they can harbor pre-neoplastic alterations (as BillN) or malignancy ${ }^{20}$. Due to the concomitant increase in western countries of intrahepatic cholangiocarcinoma, it would be useful to understand the natural history of FIHS, as they can represent a radiological manifestation of underlying pre-malignant disease: in that perspective, the ideal treatment could be an early surgery to prevent cholangiocarcinoma ${ }^{3,18}$.

Cholangiocarcinoma is the most common biliary tract malignancy, with a well known unfavorable prognosis. Currently, surgery is the only potential curative treatment but, unfortunately, the majority of patients are diagnosed at late stage or are found to be unresectable during explorative laparotomy ${ }^{3}$. Interestingly, during the last three decades, the incidence of the intrahepatic subtype of cholangiocarcinoma has increased in Western Europe ${ }^{18}$.

Cholangiocarcinoma of intrahepatic and extrahepatic bile ducts is known to develop through a multistep carcinogenesis sequence, including biliary intraepithelial neoplasia. BillN is characterized by a flat or micropapillary growth of atypical biliary epithelium. In 2007 Zen et a ${ }^{10}$. reported the results of the international consensus on its diagnostic criteria and grading.

In the last 20 years, pathologists have identified two main precursors of invasive cholangiocarcinoma, namely BillN and intraductal papillary neoplasm of bile duct, both currently included in the WHO classification of tumors of digestive system ${ }^{10}$. As expected, BillN and intraductal papillary neoplasm have been identified in the bile ducts of patients suffering of primary sclerosing cholangitis, choledochal cyst and hepatolithiasis, all well known risk factors for cholangiocarcinoma. In 2006, Zen et al. ${ }^{22}$ reported a series of 110 patients with biliary neoplasm associated to hepatolithiasis, differentiating cases of BillN and intraductal papillary neoplasm by cytokeratin and mucin immunoistochemical staining; in that series, cholangiocarcinomas arising from Bill N developed tubular adenocarcinoma, while those arising from intraductal papillary neoplasm developed either tubular or colloid carcinomas; moreover, those latter seemed to have a better survival ${ }^{16}$. Regarding the difference in tumorigenic pathways, BillN lesions seem to have higher expression of the mucin core protein MUC 1, probably favoring a more invasive phenotype with respect to cholangiocarcinomas harboring form IPNB' ${ }^{1}$. Moreover, many studies have supposed BillN and IPNB to be biliary counterparts of pancreatic intraepithelial neoplasia intraductal papillary neoplasm and intraductal papillary mucinous neoplasm of the pancreas intraductal papillary neoplasm ${ }^{8,11,13}$.

Strictly related to the topic of cholangiocarcinoma's pre-neoplastic lesions, nowadays in clinical practice another issue is emerging, regarding focal undetermined intrahepatic biliary duct strictures.

An appropriate diagnostic evaluation is of paramount importance, because it is currently unknown FIHS' natural history and if they can harbor malignancy or pre-neoplastic lesions ${ }^{19}$. Based on the accessibility of the biliary tree and the site of the lesion, biliary strictures can be evaluated by endoscopic retrograde cholangiopancreatography or percutaneous transhepatic cholangiography. Both techniques allow sampling of the strictures and therapeutic biliary stent placing. However, biliary brushing cytology, as reported by Trikudanathan et al. ${ }^{17}$ in a recent meta-analysis, has a low sensitivity (not exceeding 43\%) in detection of cholangiocarcinoma in primary sclerosing 
cholangitis patients. The same authors, in another meta-analysis, reported that fluorescence in situ hybridization (FISH) was able to increase the sensitivity up to $68 \%{ }^{12}$.

Another reported technique in the evaluation of indeterminate biliary lesions is the SpyGlass single-operator peroral cholangioscopy ${ }^{4,9}$. Woo et al. ${ }^{19}$ reported that overall accuracy of SpyGlass visual assessment and SpyBite biopsy for the diagnosis of malignancy were $96.7 \%$ and $73.6 \%$, respectively. Similar results were obtained in a Japanese large prospective multicenter study $(95.5 \% \text { and } 70.7 \%)^{9}$. Interestingly, this study reported 10 cases of intrahepatic indeterminate biliary lesions, in which accuracy values decreased (80\% and $83.3 \%$ ). A recent meta-analysis by Sun et al. ${ }^{15}$, considering the usefulness of this diagnostic tool in determining malignancy in biliary lesions, reported sensitivity and specificity of visual assessment and visual guided biopsy of $90-87 \%$ and $69-98 \%$, respectively. Currently, no study has demonstrated the ability of CT scan or MRCP, as well as endoscopic or intraductal ultrasound, to differentiate benign from malignant intrahepatic strictures.

Regarding treatment, due to the undefined possibility of FIHS to harbor malignancy, it has been advocated that stricture should be resected whenever, during the diagnostic work-up, a malignant diagnosis is suspected or of course ascertained. Yeo et al. ${ }^{20}$, in their review, proposed an interesting algorithm treatment for FIHS: after a two level diagnostic work-up, based on non-invasive and invasive diagnostic tools, in case of supposed benign stricture, cholangioscopy with or without biopsy should be performed. If a benign stricture is confirmed, treatment should be reserved only to symptomatic patients and could be surgical or non-surgical (endoscopic, percutaneous). Regarding the surgical technique, in the last decade, we have assisted to the spreading of laparoscopic liver resection world wide ${ }^{1}$ and several cases of laparoscopic liver resection for intrahepatic bile duct dilatation with associated hepatolithiasis, a condition quite similar to FIHS, have been described ${ }^{5,6,15}$. In our centre, we performed in 2019 two cases of left biliary duct stricture who underwent laparoscopic left hepatectomy with final diagnosis of BillN ${ }^{10,20}$. In a retrospective Korean series involving 24 patients who underwent surgical resection for bile duct dilatation without demonstrable mass on pre-operative imaging, Kim et al. ${ }^{7}$ found in half of patients $(n=12)$ malignancy at the final pathology. From a morphological point of view these patients, compared to those with benign bile duct stricture, showed thickening of bile duct wall $\geq 5 \mathrm{~mm}$ and regional lymph node enlargement on CT scan, abrupt cut-off and bile duct separation on cholangiogram. The prospective series by Seo et al. ${ }^{14}$ on percutaneous transhepatic cholangioscopy included 17 patients with FIHS without stones: a histopathologic diagnosis was obtained in all patients ( 9 adenocarcinomas, 1 squamous cell carcinoma, 2 hepatocellular carcinomas, 2 adenomas and 3 benign strictures). Of the nine with bile duct adenocarcinoma, eight underwent surgery and a curative resection was possible in seven patients. Interestingly, five patients had early-stage bile duct cancer in which cancer invasion was limited to the mucosa or fibromuscular layer and there was no evidence of lymph node metastasis.

\section{CONCLUSION}

It is raising the fact that FIHS can harbor pre-neoplastic lesions (BillN). The diagnostic work-up is often inconclusive in order to rule out malignancy, but in literature cholangioscopy with biopsy is emerging as a promising technique to overcome this issue, even if it is not widespread and available in every center as it deserves a specific training and equipment. Whenever the suspicion of malignancy is moderate to high, we believe that surgery is fully justified, as it can represent a kind of preventive treatment of cholangiocarcinoma. Minimally invasive liver resection in this setting could represent the optimal choice. As high level evidence in this topic is still lacking in literature, we call for national and international registers to address the issue of diagnosis and management of focal intrahepatic undetermined strictures.

\section{REFERENCES}

1. Abu Hilal M, Aldrighetti L, Dagher I, Edwin B, Troisi RI, Alikhanov $\mathrm{R}$, et al. The Southampton Consensus Guidelines for Laparoscopic Liver Surgery: From Indication to Implementation. Ann Surg. 2018;268(1):11-18. doi: 10.1097/SLA.0000000000002524.

2. Bickenbach K, Galka E, Roggin KK. Molecular mechanisms of cholangiocarcinogenesis: are biliary intraepithelial neoplasia and intraductal papillary neoplasms of the bile duct precursors to cholangiocarcinoma? Surg Oncol Clin N Am. 2009;18(2):215-24, vii. doi: 10.1016/j.soc.2008.12.001.

3. Blechacz B. Cholangiocarcinoma: Current Knowledge and New Developments. Gut Liver.2017;11(1):13-26. doi:10.5009/gnl15568.

4. Brunaldi VO, Brunaldi JE, Vollet-Filho JD, Brunaldi MO, Ardengh JC, Bagnato VS, Dos-Santos JS, Kemp R. Photodynamic therapy of extrahepatic cholangiocarcinoma using digital cholangioscopy. Arq BrasCirDig.2020;33(1):e1490.doi:10.1590/0102-672020190001e1490

5. Cai X, Wang $Y, Y u$ H, Liang $X$, Peng S. Laparoscopic hepatectomy for hepatolithiasis: a feasibility and safety study in 29 patients. Surg Endosc. 2007;21(7):1074-8. doi: 10.1007/s00464-007-9306-9.

6. Dagher I, Diop PS, Lainas P, Carloni A, Franco D. Laparoscopic liver resection for localized primary intrahepatic bile duct dilatation. Am J Surg.2010;199(1):131-5. doi:10.1016/j.amjsurg.2008.12.027.

7. Kim HJ, Lee KT, Kim SH, Lee JK, Lim JH, Paik SW, Rhee JC. Differential diagnosis of intrahepatic bile duct dilatation without demonstrable mass on ultrasonography or $\mathrm{CT}$ : benign versus malignancy. J Gastroenterol Hepatol. 2003;18(11):1287-92. doi: 10.1046/j.14401746.2003.03169.x.

8. Klöppel G, Kosmahl M. Is the intraductal papillary mucinous neoplasia of the biliary tract a counterpart of pancreatic papillary mucinous neoplasm? J Hepatol. 2006;44(2):249-50. doi: 10.1016/j. jhep.2005.11.035.

9. Kurihara T, Yasuda I, Isayama H, Tsuyuguchi T, Yamaguchi $T$, Kawabe K, Okabe Y, Hanada K, Hayashi T, Ohtsuka T, et al. Diagnostic and therapeutic single-operator cholangiopancreatoscopy in biliopancreatic diseases: Prospective multicenter study in Japan. World J Gastroenterol. 2016;22(5):1891-901. doi: 10.3748/wjg.v22. i5.1891.

10. Nagtegaal ID, Odze RD, Klimstra D, Paradis $V$, Rugge $M$, Schirmacher $\mathrm{P}$, Washington KM, Carneiro F, Cree IA; WHO Classification of Tumours Editorial Board. The 2019 WHO classification of tumours of the digestive system. Histopathology. 2020;76(2):182-188. doi: 10.1111/his.13975.

11. Nakanuma Y, Kakuda $Y$, Uesaka K. Characterization of Intraductal Papillary NeoplasmoftheBileDuctwith RespecttotheHistopathologic Similarities to Pancreatic Intraductal Papillary Mucinous Neoplasm. Gut Liver. 2019;13(6):617-627. doi: 10.5009/gnl18476.

12. Navaneethan U, NjeiB, Venkatesh PG, Vargo JJ, Parsi MA. Fluorescence in situ hybridization for diagnosis of cholangiocarcinoma in primary sclerosing cholangitis: a systematic review and metaanalysis. GastrointestEndosc. 2014;79(6):943-950.e3. doi:10.1016/j. gie.2013.11.001.

13. Rocha FG, Lee $H$, Katabi N, DeMatteo RP, Fong $Y$, D'Angelica MI, Allen PJ, Klimstra DS, Jarnagin WR. Intraductal papillary neoplasm of the bile duct: a biliary equivalent to intraductal papillary mucinous neoplasm of the pancreas? Hepatology. 2012;56(4):1352-60. doi: 10.1002/hep.25786. 
14. Seo DW, Kim MH, Lee SK, Myung SJ, Kang GH, Ha HK, Suh DJ, Min YI. Usefulness of cholangioscopy in patients with focal stricture of the intrahepatic duct unrelated to intrahepatic stones. Gastrointest Endosc. 1999;49(2):204-9. doi: 10.1016/ s0016-5107(99)70487-6.

15. Sun X, Zhou Z, Tian J, Wang Z, Huang Q, Fan K, Mao Y, Sun G, Yang $Y$. Is single-operator peroral cholangioscopy a useful tool for the diagnosis of indeterminate biliary lesion? A systematic review and meta-analysis. Gastrointest Endosc. 2015;82(1):79-87. doi: 10.1016/j.gie.2014.12.021.

16. Tajima Y, Kuroki T, Fukuda K, Tsuneoka N, Furui J, Kanematsu T. An intraductal papillary component is associated with prolonged survival afterhepatic resection for intrahepatic cholangiocarcinoma. Br J Surg. 2004;91(1):99-104. doi: 10.1002/bjs.4366.

17. Trikudanathan G, Navaneethan U, Njei B, Vargo JJ, Parsi MA. Diagnostic yield of bile duct brushings for cholangiocarcinoma in primary sclerosing cholangitis: a systematic review and metaanalysis. Gastrointest Endosc. 2014;79(5):783-9. doi: 10.1016/j. gie.2013.09.015

18. Witjes $C D$, Karim-Kos HE, Visser O, de Vries E, IJzermans JN, de Man RA, Coebergh JW, Verhoef $C$. Intrahepatic cholangiocarcinoma in a low endemic area: rising incidence and improved survival. HPB (Oxford).2012;14(11):777-81.doi:10.1111/j.1477-2574.2012.00536.x.

19. Woo YS, Lee JK, Oh SH, Kim MJ, Jung JG, Lee KH, Lee KT. Role of SpyGlass peroral cholangioscopy in the evaluation of indeterminate biliary lesions. Dig Dis Sci. 2014;59(10):2565-70. doi: 10.1007/ s10620-014-3171-x.

20. Yeo D, Perini MV, Muralidharan V, Christophi C. Focal intrahepatic strictures: a review of diagnosis and management. HPB (Oxford). 2012;14(7):425-34. doi: 10.1111/j.1477-2574.2012.00481.x.

21. Zen $Y$, Adsay NV, Bardadin $K$, Colombari R, Ferrell L, Haga $H$, Hong SM, Hytiroglou P, Klöppel G, Lauwers GY, et al. Biliary intraepithelial neoplasia: an international interobserver agreement study and proposal for diagnostic criteria. Mod Pathol. 2007;20(6):701-9. doi: $10.1038 /$ modpathol.3800788.

22. Zen Y, Sasaki M, Fujii T, Chen TC, Chen MF, Yeh TS, Jan YY, Huang SF, Nimura Y, Nakanuma Y. Different expression patterns of mucin core proteinsand cytokeratins during intrahepaticcholangiocarcinogenesis from biliary intraepithelial neoplasia and intraductal papillary neoplasm of the bile duct--an immunohistochemical study of 110 cases of hepatolithiasis. J Hepatol. 2006;44(2):350-8. doi: 10.1016/j.jhep.2005.09.025. 